\title{
Urban congestion charging: road pricing as a traffic reduction measure
}

\author{
W. Heyns ${ }^{1} \&$ C. B. Schoeman ${ }^{2}$ \\ ${ }^{1}$ Roads and Rail, Mouchel Parkman, UK \\ ${ }^{2}$ Department of Urban and Regional Planning, \\ North West University, South Africa
}

\begin{abstract}
Although traffic congestion is recognised as a major problem, the implementation of congestion reducing measures eludes most metropolitan areas suffering from traffic congestion, as many oppose the notion of being charged. Despite the best efforts of transport planners and economists, such measures have unwanted affects on the urban environment in which we live. It is therefore essential to implement congestion reducing measures with full knowledge of its likely effects as to overcome the majority of obstacles to implementation. This paper reports the results of an empirical investigation in London and formulates initiatives in the form of a package approach aimed at alleviating the negative effects of road pricing, whilst supporting sustainable development and nurturing public and political acceptance. The paper concludes that the key to dealing with the effects of road pricing, is developing an approach considering a range of differing initiatives, coordinating and managing them in the realm of the political-economic context in which they exist based upon recognising local perceptions, concerns, aspirations and solutions.

Keywords: road users, multi criteria analysis, revenue recycling, road pricing, transportation demand management, urban congestion charging, work schedule flexibility.
\end{abstract}

\section{$1 \quad$ Introduction}

Traffic congestion is a serious problem affecting most urban journeys around the world, as road user demand outstrips the supply of road space. As a result a number of alternative measures have been suggested to resolve the congestion 
problem. Congestion charging and more specifically road pricing is one of many alternative measures and has long featured in the list of preferred measures recommended by economists and transportation professionals. Numerous authors have recognised the value of pricing as a powerful instrument managing road user demand and a great deal of effort has been devoted in developing analytical models illustrating the expected results of postulated measures on traffic saturation levels.

Despite this prognosis, governments have fallen a long way short of committing themselves to strong traffic and demand management instruments, such as the introduction of road pricing. In the past, public and political opposition to road pricing has proved prohibitive. Officials have been hardpressed to persuade the public to pay for a driving privilege, which has been virtually free and is often viewed as an inviolable right. But with mounting pressure from environmentally conscious citizens and with the growing discontent that stems from unconscionably long commute times, the tide of public opinion seems poised to be reversed.

\section{Problem statement}

The problem is formulated as follows: Urban traffic congestion is recognised as an unsatisfactory situation in metropolitan areas, as road capacity does not increase in the same proportion as the volume of traffic, resulting in a wide variety of adverse consequences and impacts. Implementing road pricing as a fiscal instrument managing the excess demand for road space has definitive effects on the socio-economic, environmental and land use patterns of the urban landscape. This necessitates a better understanding of the link between road pricing and the measures supporting its sustainability and viability.

\section{Literature review}

\subsection{Previous research}

Economists have extensively explored the role played by economic incentives such as congestion charging in bringing about a more efficient allocation of road space and natural resources. Despite road pricing being identified as an attractive policy tool, most attempts to introduce economic incentives of this type in the transportation sector have failed as Jones [1] suggests. These failures it is fair to say, are not primarily due to the technical difficulties of introducing the appropriate price incentives. Rather, road pricing is rarely adopted because the public does not support the associated policy measures and because it is thought to have numerous unacceptable side effects on the urban fabric.

Although the theoretical foundation of congestion charging and road pricing have been well researched, it has been difficult to satisfactorily postulate the effects of road pricing from hypothetical, idealized situations using analytical tools, as has been the historic trend. Many authors attempted to identify methods and conditions for successful implementation and there is an extensive literature in the theory of road pricing. 


\subsection{Desk research}

In an attempt to overcome some inherent obstacles to implementation a number of authors have thought, by modelling, researching and predicting the effects of road pricing, some light might be shed on understanding and overcoming the specific difficulties in implementing road pricing (Holland and Watson [2]). Subsequently desk research identified four principle effects of road pricing. These are (i) the effect on the micro and macro economy, (ii) the effect on social welfare, (iii) the effect on land use and (iv) the effect on the environment.

Current literature suggested road pricing has an affect on the micro and macro economy measured against Pareto optimality, income and substitution effects, savings, consumption, investment and productivity, profitability and competitiveness as well as residential and business locational decisions. The fundamental unanswered empirical question here is the extent to which road pricing affects the economy in the local setting.

Road pricing also affects the social welfare of people living in the charged area (Arnott et al. [3]). In measuring the effect on the social welfare of road users and residents, current literature suggests road pricing effects road users most severely in terms of its price distortive characteristic, by forcing behavioural adjustments and distributional effects (Madsen and Jensen-Butler [4]).

Unsurprisingly theory about the effect of road pricing on land use is hard to obtain as this is an area where little empirical research has been done, possibly because road pricing has not been introduced on a wide enough scale to evaluate the effect (Stead and Banister [5]).

Congestion reducing measures is generally perceived as having a positive effect on the environment. Although there has been a considerable amount of research on road pricing, it is unclear whether road users' willingness to pay in return for a healthier environment will contribute towards road pricing's longterm acceptability (Otterström [6]).

Having identified the effects of road pricing it was necessary to identify those measures likely to sustain road pricing as a viable and acceptable policy instrument. Adler and Cetin [7] identified (i) revenue recycling, (ii) work-scheme flexibility, (iii) driver information provision and (iv) public and political acceptability as dominant supporting measures.

Revenue recycling is an effective instrument financing road maintenance, investment in public transport and brings about a degree of fairness to a charging instrument - subject to promoting (i) economic efficiency, (ii) equity and (iii) political feasibility (Litman [10]).

Flexible working hours have been promoted as a low cost approach to reduce traffic congestion (Chang and Cheng [8]). It was found that little empirical theory is available verifying how and to what extent work scheme flexibility is perceived by the public as a sustaining element in congestion charging.

Although a great deal is known about both road pricing and driver information systems in isolation, very little is known about the joint implementation of such systems and whether it has the ability to reduce traffic congestion (El Sanhouri and Bernstein [9]). 
Research by Goodwin [11] and others conclude that a major obstacle to introducing road pricing is political and public acceptability. The problems associated with introducing road pricing and overcoming the political implementation problems are extremely hard to solve. Emmerink et al. [11] label congestion pricing as "an intrinsically unpopular policy, which will always meet opposition from different angles". Essentially the implementation of road pricing will depend on striking a balance between the determinants to implement and the obstacles to implementation. The most commonly cited obstacles to implementation where issues relating to (i) problem perception, (ii) mobility related social norms, (iii) fairness of pricing, (iv) skepticism and uncertainty, (v) impacts on business viability and (vi) political will.

\section{$4 \quad$ Empirical results}

This section presents a summary of the findings, conclusions, viewpoints and insights made, reporting the essence of the empirical investigation.

\subsection{Main findings and conclusions}

\subsubsection{Effect on the economy}

Congestion charging has had a very insignificant effect on the micro and macro economy of London. Businesses consulted indicated no apparent change in their competitiveness or profitability apart from the retail and distribution sectors. Overall, only a small percentage admitted to considering relocating outside the congestion zone as a result of the detrimental impact on their long-term competitiveness and profitability. Strikingly, these businesses form part of the natural "churn rate" of businesses leaving the area due to leases expiring, internal business plan related reasons and other factors. Residents have indicated a small income effect but a more significant substitution effect which - accounts for the significant modal shift.

Interpreting the effects of congestion charging per se has proven rather difficult as non-economic influences, other negative global economic impacts and adverse whether conditions have influenced business performance in general terms in 2003. The findings are somewhat contrary to mainstream evidence and modulation, reflecting the difficulties involved in mapping the actual effects of road pricing.

\subsubsection{Effect on social welfare}

A significant finding, which was not entirely unexpected, was that the charge significantly altered road user behaviour, being responsible for extensive modal shift in the capital. The shift was predominantly from journeys undertaken by car to using public transport such as buses, underground services and overland railway services. The remaining road users paying the charge and continuing to travel have made adaptations to their travel behaviour manifested most strongly in adjusted departure times and route deviations. Alternatives to motorised travel such as walking and cycling remain unpopular mainly due to commuting 
distances not being practical in all circumstances. Respondents are still not keen to use a car pool which confirms previous research.

The charge does affect the lower income group proportionally more than the higher income group and no income group is able to shift the tax burden imposed by the charge to their employers.

\subsubsection{Effect on land use}

No significant trend or evidence could be found confirming the effects of congestion charging on land use planning, density of development, clustering and or land use mix. Land use functions that are greatly dependent on one-to-one business contact were found likely to decentralise from the congestion zone. Planning Authorities have recommended that higher order office functions and high-density residential functions in close proximity be encouraged within the congestion charging area. The planning process will accommodate land use changes and demands as a result of the charge based on local decision making. A great need has been expressed and identified for a plan led integrated land use planning and transport strategy approach whereby land use discourages the need to travel or helps to shorten the distances travelled.

\subsubsection{Effect on environment}

Pro-environmental stakeholders have concurred with the emission and accidentreducing capabilities of road pricing on the grounds that it reduces land take, increases air quality and leads to a cleaner environment. However the environmentalists have warned of other factors, such as climatical change, improving vehicle technology and domestic heating patterns having a more significant impact on the environment than congestion charging. None the less, road pricing's potentially positive side effects have, however, been embraced by environmentalists as another instrument in the spectrum of problem solving solutions.

\subsubsection{Revenue recycling}

The investment of the revenue from congestion charging in road network improvements, public transport and maintenance was perceived as an important condition to the introduction of road pricing and one which would undoubtedly sustain its acceptability and viability. Respondents would rather see the revenue earmarked to public transport improvements than to reducing their income tax contributions or indeed used for any other purpose.

\subsubsection{Work schedule flexibility}

Many respondents felt work schedule flexibility is a useful tool to help relieve traffic congestion. Amongst the lower income group this supporting factor was less favoured because of problems with more flexibility in terms of departure times and domestic and social arrangements. Even though employers allow flexible working conditions, this does not trigger automatic use, but it is perceived and recognised as a feasible and inexpensive tool when combined with road pricing for reducing traffic congestion through forced behavioural adjustments. 


\subsubsection{Driver information provision}

A significant percentage of road users divert from their normal route following en-route and pre-route warning of traffic congestion ahead. The provision of driver information facilitates more efficient use of the existing road network. By developing information technology instruments even greater efficiency gains in road use will be achieved and should therefore be encouraged. Again, providing driver information is a good example of forcing behavioural adjustments to achieve reduced traffic levels.

\subsubsection{Public and political acceptance}

The main obstacle to implementing congestion charging is to make it agreeable and acceptable to the majority of the public. Their opposition is based upon scepticism, uncertainty, fears regarding invasion of privacy and the notion that their "right to travel" will be violated. Apart from the negative publicity congestion charging has received, it has fundamentally been accepted by a large percentage of respondents who recognise that traffic congestion is a serious problem in their capital and that the only solution is to take drastic measures. The backing of politicians was identified as being necessary in order to overcome these obstacles and scepticism. It was also acknowledged that open and accountable public and stakeholder consultation would prevent road pricing being seen as an instrument forced upon the public.

\subsection{Locally perceived problem areas or obstacles to successful implementation}

The results collectively identified several publicly perceived problem areas, concerns and obstacles, which obstruct the efficient and sustainable implementation of road pricing. The concerns cited most often by respondents were about business profitability and competitiveness, the need for the promotion of an integrated land use and transport strategies and the lack of transparency in the revenue recycling process. These concerns form the basis for developing options or policy alternatives to overcome the problems and obstacles.

\subsection{Multi criteria analysis}

To overcome these problem areas and concerns, multi criteria analysis was used to formulate a number of policy options in pursuit of solutions. Measured against determined criteria, the options were ranked according to stakeholder perceptions, thereby identifying four policy options publicly perceived as solutions to identified problems. These were:

- Promoting public acceptability through transparency, consultation and democratic choice

- Promoting the integration of land use and transport strategies

- Promoting efficient and equitable use of revenue

- Deploying a portfolio of fiscal and command and control instruments to abate environment damaging emissions. 


\section{Recommendations}

\subsection{Contextual framework}

A world-class transport system will not come easily, but achieving it is not impossible if bold and imaginative solutions such as congestion charging are tried and tested and the political will to carry them out exists. It is important to succeed because a high standard of transport efficiency enhances the quality of life, is good for economic growth and helps maintain the competitive advantage cities experience. Whatever the individual preferences of commuters and the various transport choices cities offer, the overall land use and transport system must provide high quality public transport services which are reliable, convenient to use, accessible, comfortable, safe, speedy and affordable for the majority of users.

The recommendations were subsequently made within the context of considering the following design elements: (i) residential integration, (ii) environmental awareness, (iii) traffic planning, (iv) urban design, (v) infrastructure maintenance, (vi) economic growth, (vii) accessibility and (viii) stakeholder consultation.

\subsection{Approach to successful charging}

A package approach was developed by incorporating these elements into four initiatives based upon the identified policy options. These are briefly summarised below.

\subsubsection{Promote public acceptability through transparency, consultation and democratic choice.}

To overcome many of the obstacles posed to implementation, the first initiative is to plan, develop and implement a procedure that takes account of the difficulties identified in the local setting. This is likely to be achieved by implementing an initiative incorporating the following four steps.

The first step is to recognize and discuss the problem. The responsibility for recognising the problem extends beyond that of the public. It is essentially a task for Central government, Local Highway Authorities, Planning Authorities, politicians and pressure groups to identify and respond to the difficulties. In doing so five general arguments have to be won before congestion charging can be put through public consultation. These are:

i. There must be a need to take some action to restrain traffic levels

ii. Agree that road pricing is a practical and effective measure

iii. Address equity concerns

iv. The benefits of road pricing are significant, obvious and easily understood

v. Alternative modes of public transport exist.

In the next step it is critical that a visible consultation process is conducted, typically by the Instigating Authority, illustrating that congestion charging will be designed having taken into account the views of all stakeholders and only if 
there is broad support in principle. The third step involves open and democratic decision making accepting or rejecting the program finally followed by, implementing and evaluating the scheme by identifying criteria measuring the scheme impacts then reporting the results, achievements and benefits and feeding those back into the scheme design making any appropriate alterations.

\subsubsection{Promote the integration of land use and transport strategies}

In finding suitable and sustainable solutions to overcome persistent traffic congestion problems, a multi-pronged initiative was devised to achieve this without prejudging the relative contributions of different modes of transport. Fundamentally the initiative promotes the integration of land use and transport strategies by (i) specifying the role of planning, public transport and promoting choices, (ii) identifying how the road network will be managed and (iii) identifying how driver information technology will be integrated.

In integrating planning and transport and by promoting travel choices four elements must be incorporated into the initiative. They are (i) spatial planning, (ii) measures reducing the need to travel and offering choices, (iii) investing in public transport and (iv) considering the role of traffic control.

In terms of identifying how the road network will be managed, active and coordinated management of the road network is a key step in tackling congestion and an essential supporting instrument to congestion charging. Here (i) better management of roadworks, (ii) better management of works by utility companies ("street works"), (iii) incident management and (iv) preparing for adverse weather conditions are integral actions part of the approach.

Promoting driver information technology included elements such as: (i) the current state of the road network, (ii) where traffic congestion is, (iii) weather conditions and (iv) incidents/collisions.

\subsubsection{Implement efficient and equitable use of revenue}

In considering how to spend the revenue raised from congestion charging three prerequisites have been identified which must be adhered to if the money is to be spent to a socially optimum level. They are: (i) economic efficiency, (ii) equity and (iii) political feasibility.

Economic efficiency is concerned with the use of society's resources to achieve maximum net benefit. From an overall economic efficiency perspective the revenue must be used to benefit society and the greater the benefit, the more economically efficient the program. There is no requirement, however, that the money be allocated in any particular way from an efficiency point of view.

Greater economic efficiency in the public transport sector can be achieved by considering the following elements: (i) investing in infrastructure through maintenance and improvements, (ii) investing in public transport services to enhance reliability, safety and quality, (iii) improve fairness among beneficiaries via benefit taxation and (iv) using revenue to improve the efficiency of managing public transport and demand management measures.

Equity in revenue distribution can be achieved by implementing the benefit principle of taxation by considering earmarking of revenue. Similarly, the ability to pay principle of taxation should be considered in terms of revenue recycling. 
Typical approaches dependant on local acceptability and circumstances are (i) considering cash rebates to the very lowest income group paying the charge, (ii) vehicle tax subsidy to the lowest income group paying the charge, (iii) considering reduced congestion charge payments, (iv) VAT exemption on fuel in terms of a means test, (v) fund business centre transportation facilities and services for the disabled and elderly and (vi) proportionally refund those disabled and pensioners who pay the charge.

In achieving public and political feasibility the road pricing programs must be attractive and transparent to voters. The redistribution program must recognise and reflect popular perceptions and political will power. To be publicly feasible, the way in which revenues are spent must be perceived as significantly beneficial to people.

\subsubsection{Deploy a portfolio of fiscal and command and control instruments to abate environment damaging emissions}

The final initiative to be perused as part of a package approach is that of reducing environment damaging emissions. Transport activities are inextricably linked with environmental damage. Road pricing reduces the number of vehicles entering an area thereby directly reducing not only traffic congestion but also emission and pollution levels and environmental damage. However, road pricing is not designed to primarily reduce emissions nor is it the premise for its success or failure.

To this end a portfolio of integrated fiscal and command and control instruments should be considered or deployed to strengthen the case for road pricing. These include: (i) incentive based instruments such as emission subsidies, (ii) regulation of vehicle activity by promoting cleaner vehicle technology and imposing fuel efficiency standards for cars and (iii) fiscal measures such as green taxes, emission taxes, product taxes and fuel taxes.

\section{Conclusion}

The success of urban congestion charging does not only depend on the input and dedication of one stakeholder or instigating Authority but rather a multitude of stakeholders, Authorities and interest groups. The public is central to the achievement of a significant degree of acceptance. Without its support charge evasion and other negative side effects may occur. The package approach recognises these aspects and by amalgamating the initiatives discussed above, stands to overcome a great deal of pessimism and lead to real insight into the mechanics of road pricing. Fundamentally, an approach has to be developed, adopted and implemented, based upon recognising local perceptions, concerns, aspirations and locally acceptable solutions in addressing traffic congestion and the effects it has on the environment in which we live. It sets the stage for positive problem solving thought through an open and accountable process. 


\section{References}

[1] Jones, P., Urban road pricing: public acceptability and barriers to implementation. Road pricing, traffic congestion and the environment: issues of efficiency and social feasibility, eds. K.J. Button \& E.T. Verhoef, Edward Elgar: Cheltenham, pp. 263-284, 1998.

[2] Holland, E.P. \& Watson, P.L., Traffic restraint in Singapore: 1: measuring the effects of the area license scheme; 2: some design factors in traffic pricing schemes. Traffic engineering and control, 19(1), pp. 14-25, 1978.

[3] Arnott, R., de Palma, A. \& Lindsey, R., The welfare effects of congestion tolls with heterogeneous commuters. Journal of transport economics and policy, 28, pp. 139-161, 1994.

[4] Madsen, B. \& Jensen-Butler, C., Modelling the local economic impacts of road pricing. Institute of Local Government Studies, Denmark, SOM Publication, 46. http://www.akf.dk/som/pdf/som46.pdf

[5] Stead, D. \& Banister, D., Influencing mobility outside transport policy. Innovation, 14(4), pp. 315-330, 2001.

[6] Otterström, T., Pricing of environmental impacts of emissions from road traffic - recent and present research in Finland. Science of the total environment, 169(1-3), pp. 311-319, 1995.

[7] Adler, J.L. \& Cetin, M., A direct redistribution model of congestion pricing. Transportation research part B: methodological, 35(5), pp. 447-460, 2001.

[8] Chang, S-K. \& Cheng, C.C., A time-varying congestion pricing model for optimization of transport corridor. National Taiwan University, Taipei, http://www.wsdot.wa.gov/ppsc/research/TRB_Special/TRB2003001037.pdf

[9] El Sanhouri, I. \& Bernstein, D., 1994. Integrating driver information and congestion pricing systems. Transportation research record, 1450, pp. 44-50, 1994.

[10] Litman, T., Using road pricing revenue: economic efficiency and equity considerations. Victoria Transport Policy Institute, Victoria, http://www.vtpi.org/revenue.pdf

[11] Emmerink, R.H.M., Nijkamp, P. \& Rietveld, P., Is congestion pricing a first-best strategy in transport policy?: a critical review of arguments. Environment and planning B, 22, pp. 581-602, 1995. 